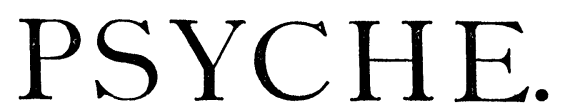

ORGAN OF THE CAMBRIDGE ENTOMOLOGICAL CLL'B EDITED BY GEORGE DIMMOCK AND B. PICKMAN MANN.

Vol. II.] Cambridge, Mass., February, 1879. [No. 58.

\title{
On the Repugnatorial Glands in Eleodes.
}

The repugnatorial glands of Eleodes gigantea and $\boldsymbol{E}$. dentipes are situated on both sides of the intestinal tract, imbedded in the fat-bodies. They are two reddish-brown, semi-bilobed pieces, cylindrical at the upper, longer lobe and more flattened at the lower, shorter part, the latter being on the inner side, as the figure shows. Their extent is from the base of the last up to the middle of the second integumental segment, and they have an average length of $6.5 \mathrm{~mm}$. Both $\boldsymbol{E}$. gigantea and $\boldsymbol{E}$. dentipes, male and female, possess these glands, and on teasing the living specimens

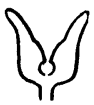

Fig. 10 . in the breeding cage, they stand on their anterior and middle legs, holding the abdomen high up, and spirting the contents of the glands left and right. I have handled several hundred live specimens, and, in every case, the spirting had a sidewise direction. The liquid stains the human skin, and the stains are not easy to remove. In some cases, when the secretion is spirted on a glass slide, it solidifies within a few seconds, forming an orange-colored magma of minute crystals; in other cases it only partially crystallizes, and in others it remains entirely liquid. It is, in all cases, of an acid reaction, and of an intensely penetrant odor, causing the eye to lachrymate. It is soluble in water, alcohol and ether. Boiled with concentrated sulphuric acid and alcohol an ethereal aromatic vapor is produced, indicating the presence of one or more organic acids. The smell of the glandular secretion is to my knowledge incomparable with anything else, and very peculiar. Having tested 
for valerianic acid in the usual way with neutralized soda-solution upon sesquichloride of iron, no red precipitate of valerianate of iron was formed, nor have I obtained a bluish-white opalescent liquid of butyrate of copper on adding acetate of copper. Uric acid was also found to be absent, on treating with nitric aeid and ammonia in the usual way; neither could I detect formic or acetic acid, nor did boiling with caustic soda libərate ammonia. A few drops of the secretion, put on a piece of dry caustic soda, turned at first dark green, became in a few seconds dirty brown, and cleared up to a brownish red after several hours. So far I am not aware of the constituents of the secretion, and, on sending some of it to Prof. Chandler, asking his kind advice, I was told that a payment of sixty to seventy-five dollars, in advance, would be necessary to have an accurate analysis made.

The secretion was gathered gradually, by holding live specimens into a test-tube containing 10 grams of dry caustic soda. About 60 drops have accumulated during a period of three months.

Carl F. Gissler.

\section{Attacks of Native Insects upon Imported Trees.}

It is often stated that foreign trees, and other plants imported into a country, are not attacked by the insects peculiar to the new surroundings. The presumed immunity is even quoted as an advantage in the use of such trees for forest trees. But the immunity is apparently only presumed, at least for plants and trees after their entire acclimatization. When I was a boy I saw extensive plantations of Pinus strobus and of Robinia pseudacacia, which grew excellently and seemed not to be attacked by native insects. This was between 1824 and 1830 . Later, things have changed considerably; nevertheless Ratzeburg contends that at least deciduous trees are attacked less (as he states it to be a common fact) than pine trees. Therefore exotic oaks near by indigenous ones infested by Chrysomela and Tenthredo are attacked less. The Pinus strobus according to Noerdlinger, is attacked even more than European pine, being damaged together by Scolytus polygraphus, S. piniperda, 

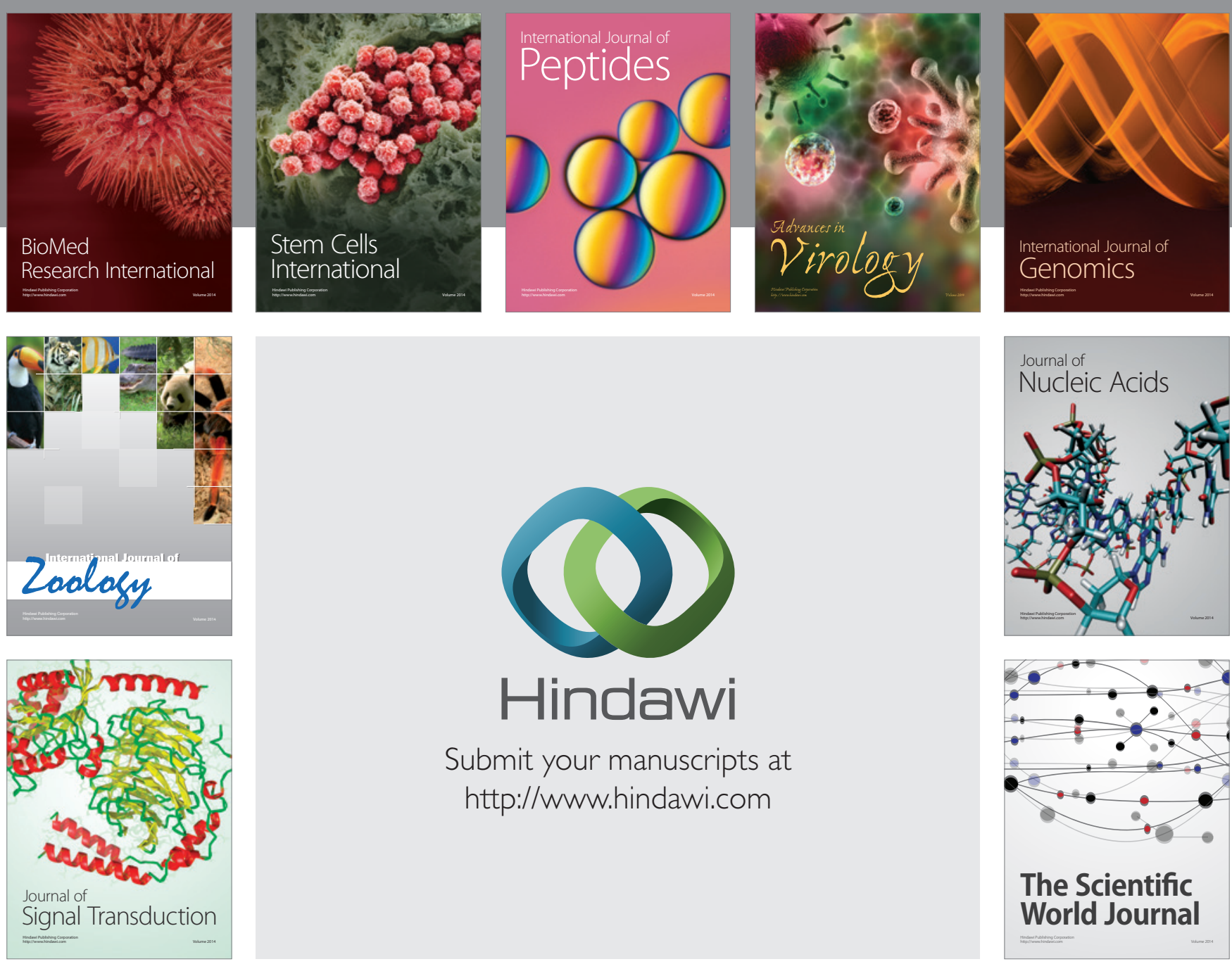

Submit your manuscripts at

http://www.hindawi.com
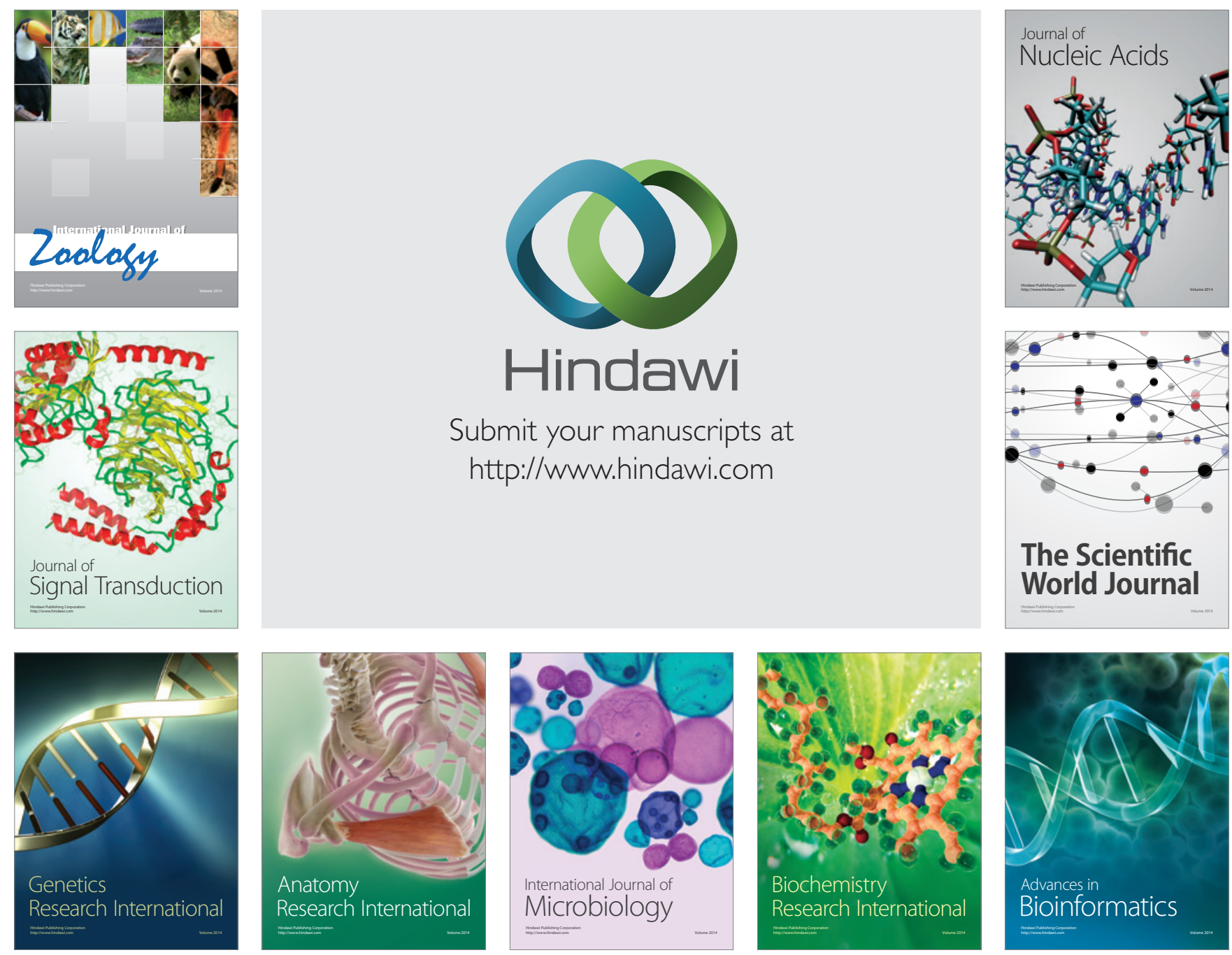

The Scientific World Journal
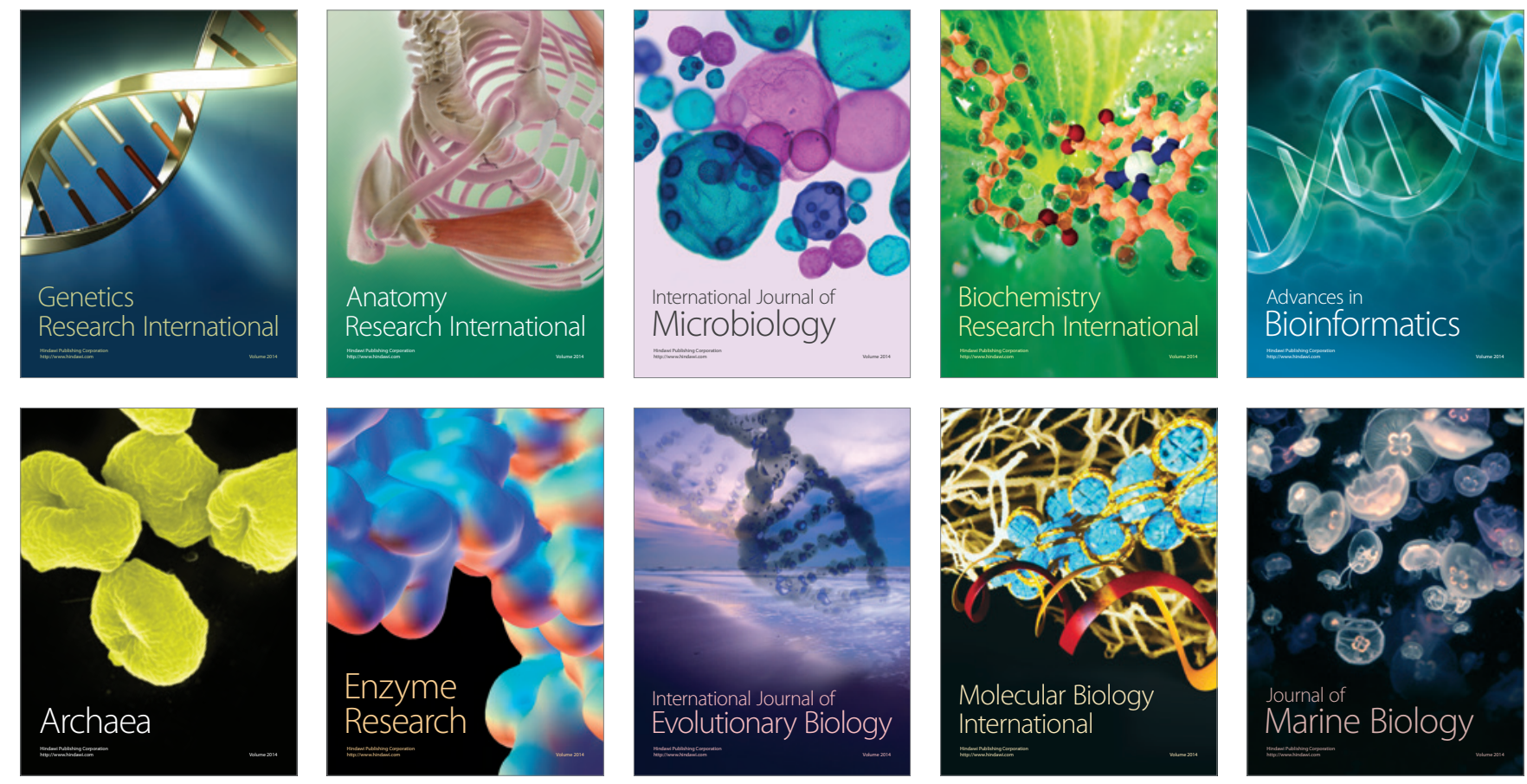